\title{
PENINGKATAN HASIL BELAJAR IPA DI SD DENGAN MENGGUNAKAN METODE PQ4R
}

\author{
Meirza Nanda Faradita \\ PGSD, FKIP Universitas Muhammadiyah Surabaya \\ meirzananda@fkip.um-surabaya.ac.id
}

\begin{abstract}
Abstrak
Pendidikan IPA erat kaitannya dengan pembelajaran melalui benda konkret dan melalui pengalaman yang nyata. Berdasarkan observasi yang telah dilakukan di kelas kelas V Al-Kholiq SD Muhammadiyah 8 Surabaya menunjukkan bahwa hasil belajar siswa dalam pembelajaran kompetensi dasar IPA dibawah kriteria ketuntasan minimal (KKM). Penelitian ini bertujuan untuk meningkatkan hasil belajar dengan menggunakan teknik PQ4R. Penelitian ini menggunakan Penelitian Tindakan Kelas (PTK) yang dilaksanakan di kelas V Al-Kholiq SD Muhammadiyah 5 Surabaya. Subjek penelitian sebanyak 15 siswa laki-laki dan 10 siswa perempuan. Teknik pengumpulan data dengan tes. Siswa dikatakan tuntas apabila hasil belajarnya di atas KKM $\geq 75$ dan prosentase ketuntasan belajar siswa di kelas tersebut $\geq 80$.

Pelaksanaan penelitian terdiri atas siklus I dan Siklus II dengan rentang waktu 7 hari. Hasil penelitian siklus I menunjukkan bahwa rata-rata kelas mendapatkan nilai 75,4 dengan prosentase ketuntasan belajar siswa $72 \%$. Hal ini belum dapat dikatakan tuntas, sehingga dilakukan pembelajaran lagi di siklus II. Pada siklus II hasil rata-rata kelas mendapat 81,8 dan hasil ketuntasan belajar siswa adalah $80 \%$. Secara klasikal pembelajaran dikatakan tuntas. Pembelajaran menggunakan metode PQ4R dapat meningkatkan hasil belajar IPA siswa kelas V Al-Kholiq.
\end{abstract}

Kata kunci : IPA, Metode PQ4R, Hasil Belajar

\begin{abstract}
Science education is closely related to learning through concrete objects and through real experience. Based on observations made in class V of Al-Kholiq Muhammadiyah 8 Surabaya Elementary School showed that student learning outcomes in basic science competency learning under the minimum completeness criteria (KKM). This study aims to improve learning outcomes using the PQ4R technique. This study used Classroom Action Research (CAR) carried out in class $V$ Al-Kholiq Muhammadiyah 5 Elementary School Surabaya. The research subjects were 15 male students and 10 female students. Techniques for collecting data with tests. Students are said to be complete if their learning outcomes are above KKM $\geq 75$ and the percentage of students' mastery learning in that class is $\geq 80$.

The implementation of the study consisted of cycle I and Cycle II with a span of 7 days. The results of the first cycle study showed that the class average got a value of 75.4 with a percentage of $72 \%$ student learning completeness. This cannot be said to be complete, so learning is carried out again in cycle II. In the second cycle the results of the class average got 81.8 and the results of student learning completeness were $80 \%$. Classical learning is said to be complete. Learning using the PQ4R method can improve the science learning outcomes of class $V$ students of Al-Kholiq.
\end{abstract}

Keywords: Science, PQ4R Method, Learning Outcomes 


\section{PENDAHULUAN}

Pendidikan di Indonesia ini tidak terlepas dengan mata pelajaran IPA. IPA berhubungan dengan alam atau bersangkut paut dengan alam, science artinya ilmu pengetahuan. IPA atau science itu pengertiannya dapat disebut sebagai ilmu tentang alam. Ilmu yang mempelajari peristiwa-peristiwa yang terjadi di alam ini. Pendidikan IPA erat kaitannya dengan pembelajaran melalui benda konkret dan melalui pengalaman yang nyata. Sehingga penting bagi guru dalam memperhatikan cara menanamkan konsep IPA dengan benar sehingga tidak ada kesalahan siswa saat memahami konsep IPA.

Berdasarkan observasi yang telah dilakukan di kelas kelas V Al-Kholiq SD Muhammadiyah 8 Surabaya pada tanggal 29 Oktober 2018, kami menemukan permasalahan yaitu rendahnya hasil belajar siswa dalam pembelajaran kompetensi dasar IPA dilihat dari hasil penilaian harian yang dibawah kriteria ketuntasan minimal $(\mathrm{KKM})<75$ dengan presentase ketuntasan belajarnya 25\%. Sejalan dengan penelitian dari (Wondal, 2016) yang menyebutkan hasil observasi nilai Ulangan Harian masih di bawah KKM $<65$ dengan presentase ketuntasan belajarnya $18 \%$. Banyak siswa yang mengalami kesulitan dalam pembelajaran IPA. Mereka menganggap IPA sebagai pelajaran yang sulit sehingga siswa tidak memiliki ketertarikan saat pelajaran IPA. Salah satu faktor yang mempengaruhi rendahnya hasil belajar siswa dalam pelajaran IPA adalah kurang adanya keberagaman metode pembelajaran yang membuat siswa bosan. Sebagai salah satu komponen pengajaran, metode menempati peranan yang tidak kalah pentingnya dari komponen lainnya dalam kegiatan belajar mengajar. Penggunaan metode yang tepat dan bervariasi akan dapat dijadikan sebagai alat motivasi ekstrinsik dalam kegiatan belajar mengajar di sekolah.

Berdasarkan uraian di atas peneliti ingin menggunakan metode pembelajaran PQ4R untuk meningkatkan hasil belajar IPA di SD. Metode yang dapat digunakan dalam pembelajaran IPA di Sekolah Dasar yaitu metode PQ4R karena metode ini dapat menumbuhkan cara berfikir kritis dan mengingat apa yang siswa baca serta dapat memicu proses belajar aktif (Suprijono, 2015). Metode PQ4R adalah salah satu bagian dari strategi elaborasi (Trianto Ibnu Badar Al-Tabany \& Tutik, 2014). Metode pembelajaran PQ4R dapat digunakan untuk membantu siswa mengingat apa yang siswa baca dan dapat membantu proses belajar mengajar di kelas yang dilaksanakan dengan membaca buku pelajaran secara berkelompok. Siswa diminta untuk mengeksplorasi kemampuannya membuat struktur berpikir sebelum membaca dengan menyusun pertanyaanpertanyaan yang menjadi acuan bagi siswa untuk menggali informasi yang dibutuhkan dari teks bacaan. Kemudian siswa secara mandiri membaca teks sembari mencari jawaban dari pertanyaan yang telah dibuatnya. Metode pembelajaran PQ4R lebih banyak memberikan kesempatan kepada siswa untuk membaca sebagai sebuah proses interaktif. Hal ini apa yang diharapkan dapat tercapai, sehingga tidak hanya siswa tertentu yang aktif dalam pembelajaran, melainkan seluruh siswa yang mengikuti diskusi dapat aktif bekerjasama dalam memecahkan masalah.

Tahapan yang harus dilakukan dalam metode pembelajaran PQ4R adalah: 1) preview, agar siswa membaca selintas dengan cepat; 2) question, mengajukan 
pertanyaan-pertanyaan pada diri sendiri untuk setiap pasal yang ada pada siswa; 3 ) read, membaca buku dan bahan bacaan lainnya dengan efektif, yaitu dengan cara, pikiran siswa harus memberi reaksi terhadap apa ynag dibacanya; 4) reflection, proses pengendapan pengalaman yang telah dipelajari, yang dilakukan dengan cara mengurutkan kembali kejadian atau peristiwa pembelajaran yang telah dilaluinya; 5) recite, siswa diminta untuk mengingat kembali informasi yang telah dipelajari dengan menyatakan butir-butir yang penting dengan nyaring dan dengan menanyakan dan menjawab pertanyaan; 6) review, siswa diminta untuk membaca catatan singkat (inti sari) yang telah dibuatnya, kemudian siswa diarahkan agar mengulang kembali seluruh isi bacaan bila perlu dan sekali lagi menjawab pertanyaan yang telah dibuatnya. dengan adanya tahapan di atas, diharapkan siswa dapat belajar dengan aktif sehingga hasil belajar IPA dapat meningkat (Yulistiati, Rosyidi, \& Ariyanto, 2012).

Peneliti sebelumnya juga berpendapat bahwa dengan metode pembelajaran PQ4R dapat meningkatkan hasil belajar. Penggunakan strategi pembelajaran PQ4R dapat meningkatkan kualitas pembelajaran IPA berbantu media powerpoint (Rahayu \& Hartati, 2016). Strategi PQ4R dapat meningkatkan komunikasi matematis serta kemandirian belajar siswa (Tandililing, 2011). Maka dapat dirumuskan bahwa apakah dengan menggunakan metode pembelajaran PQ4R dapat meningkatkan hasil belajar siswa dalam pembelajaran IPA di SD.

\section{METODE PENELITIAN}

Jenis penelitian yang akan dilaksanakan adalah Penelitian Tindakan Kelas (PTK). Penelitian Tindakan Kelas (PTK) adalah penelitian yang dilakukan oleh guru di dalam kelasnya sendiri melalui refleksi dengan tujuan untuk memperbaiki kualitas proses pembelajaran dikelas, sehingga hasil belajar siswa dapat meningkat (Daryanto, 2014). PTK dilaksanakan melalui tahapan-tahapan yang dikenal dengan istilah siklus (daur). Siklus dalam PTK meliputi 4 tahap, yaitu perencanaan (planning), pelaksanaan (acting), pengamatan (observing), dan refleksi (reflecting) (Widayati, 2008).

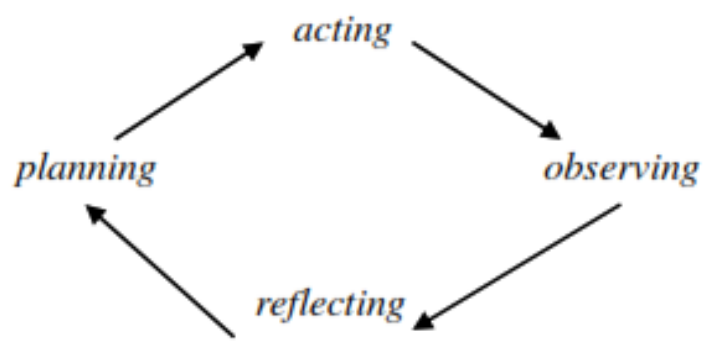

Gambar 1 Tahap-Tahap dalam PTK

Penelitian ini dilaksanakan di SD Muhammadiyah 5 Surabaya, dengan objek penelitian siswa kelas V Al-Kholiq yang terdiri atas 25 siswa dengan komposisi 15 siswa laki-laki dan 10 siswa perempuan. Waktu penelitian dilaksanakan pada bulan November 2018. Prosedur penelitian ini menggunakan 2 siklus, pada siklus I dilaksanakan pada 5 November 2018 sedangkan siklus ke II dilaksanakan pada 12 November 2018. Pengumpulan data penelitian 
menggunakan metode tes hasil belajar. Instrument data yang digunakan adalah lembar tes. Teknis analisis data yang digunakan adalah:

Keterangan:

$$
\mathrm{P}=\frac{f}{N} \times 100 \%
$$

Sumber:(Daryanto, 2014:6)

$\mathrm{P}=$ Prosentase

$\mathrm{f}=$ Jumlah skor yang didapat siswa

$\mathrm{N}=$ Jumlah skor maksimum

Siswa dikatakan mencapai ketuntasan belajar apabila telah mencapai hasil belajar $\geq 75$. Sedangkan satu kelas dapat dikatakan tuntas belajar apabila didalam kelas rata-rata mendapat $\geq 80 \%$ yang telah mencapai nilai $\geq 75$ yang dapat dihitung dengan menggunakan statistik deskriptif.

\section{HASIL DAN PEMBAHASAN}

Kemampuan siswa dalam pembelajaran kompetensi dasar IPA cukup rendah sebelum menggunakan metode PQ4R. Setelah menerapkan metode PQ4R dalam pembelajaran IPA hasil belajar siswa dapat meningkat. Berikut ini presentase hasil belajar siswa kelas V Al-Kholiq:

\section{Tabel 1 Prosentase Hasil Belajar Siswa Siklus I}

\begin{tabular}{clc}
\hline No. & \multicolumn{1}{c}{ Uraian Hasil } & Tes Siklus I \\
\hline 1. & Nilai KKM & 75 \\
\hline 2. & Nilai Rata-Rata Kelas & 75,4 \\
\hline 3. & Jumlah siswa yang belum tuntas belajar & 7 siswa \\
\hline 4. & Jumlah siswa yang tuntas belajar & 18 siswa \\
\hline 5. & Prosentase Ketuntasan Belajar & $72 \%$ \\
\hline
\end{tabular}

Dari hasil tabel di atas diperoleh data bahwa pada siklus I sebanyak 18 siswa tuntas belajar IPA, dan 7 siswa yang belum tuntas belajar IPA, dan prosentase ketuntasannya adalah $72 \%$ dengan nilai rata-rata kelas 75,4 . Artinya kelas V Al-Kholiq akan melanjutkan pembelajaran IPA dengan menggunakan metode PQ4R di siklus II agar dapat memperoleh prosentase ketuntasan belajar $\geq 80 \%$ dengan $\mathrm{KKM} \geq 75$.

Tabel 2 Prosentase Hasil Belajar Siswa Siklus II

\begin{tabular}{clc}
\hline No. & \multicolumn{1}{c}{ Uraian Hasil } & Tes Siklus II \\
\hline 1. & Nilai KKM & 75 \\
\hline 2. & Nilai Rata-Rata Kelas & 81,8 \\
\hline 3. & Jumlah siswa yang belum tuntas belajar & 5 siswa \\
\hline 4. & Jumlah siswa yang tuntas belajar & 20 siswa \\
\hline 5. & Prosentase Ketuntasan Belajar & $80 \%$ \\
\hline
\end{tabular}

Berdasarkan hasil tabel di atas diperoleh data bahwa pada siklus II sebanyak 20 siswa tuntas belajar IPA, dan 5 siswa yang belum tuntas belajar IPA, dan prosentase ketuntasannya adalah $80 \%$ dengan nilai rata-rata kelas 81,8. 
Artinya kelas V Al-Kholiq telah mengalami ketuntasan belajar IPA, karena prosentase ketuntasan belajar $\geq 80 \%$. Maka dari itu, dapat dikatakan bahwa dengan menggunakan metode PQ4R dapat meningkatkan hasil belajar IPA.

Dari tabel diatas, berikut ini disajikan grafik presentase hasil belajar siswa siklus I dan II:
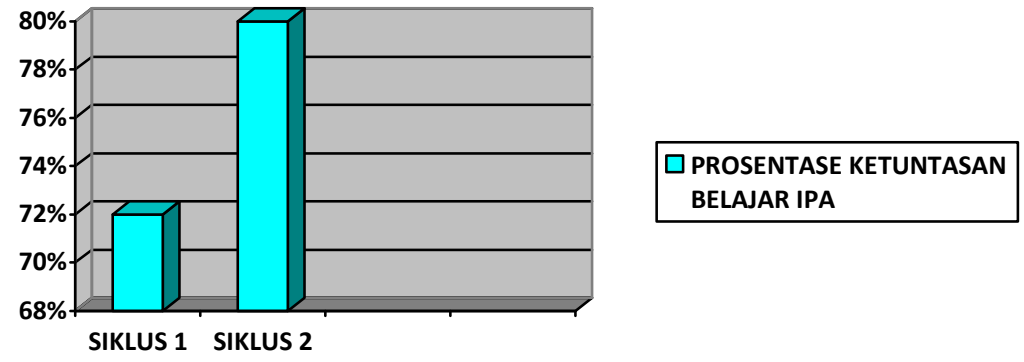

\section{Grafik 1 Prosentase Hasil Belajar Siswa Siklus I dan II}

Dilihat dari grafik di atas, diperoleh data bahwa pada siklus I prosentase ketuntasan belajar IPA adalah $72 \%$ sehingga belum dapat dikatakan tuntas karena $\leq 80 \%$. Maka peneliti mengadakan pembelajaran kembali di siklus II dengan prosentase ketuntasan belajar IPA yaitu $80 \%$. Prosentase ketuntasan belajar meningkat $8 \%$, sehingga dapat dikatakan bahwa kelas V Al-Kholiq SD Muhammadiyah 8 Surabaya mengalami peningkatan hasil belajar IPA dengan menggunakan Metode PQ4R.

Berdasarkan hasil penelitian yang telah dilakukan di SD Muhammadiyah 8 Surabaya pelaksanaan pembelajaran IPA yang sebelumnya siswa kurang mampu memahami materi namun dengan menggunakan metode PQ4R siswa terlihat lebih mudah untuk memahami materi. Hal itu dibuktikan dengan adanya peningkatan pada hasil belajar siswa setelah menerapkan metode PQ4R sebagai salah satu cara untuk memberikan pembelajaran yang menyenangkan.

Metode PQ4R mengajarkan siswa untuk mengingat apa yang telah dibaca (Indrawati, Riyadi, \& Matsuri, 2014). Dengan menggunakan metode PQ4R dapat membantu siswa untuk mengingat konsep yang telah dipelajari dan dapat meningkatkan keterampilan dalam bertanya dan juga mengutarakan pengetahuannya. Metode PQ4R juga memberi kesempatan kepada siswa untuk mengembangkan diri dan mampu dalam memecahkan masalah sendiri dengan menemukan informasi yang sudah didapatnya.

Penerapan metode PQ4R pada siklus I nilai rata-rata hasil belajar siswa dalam pembelajaran kompetensi dasar IPA pada siklus I presentase hasil belajar siswa yang tuntas adalah $72 \%$ sehingga belum dikatakan tuntas. Selanjutnya pada siklus II dengan perlakuan yang sama dilakukan pembelajaran menggunakan metode PQ4R dan didapatkan presentase hasil belajar siswa yang tuntas adalah $80 \%$. Metode PQ4R dapat meningkatkan hasil belajar siswa, karena model pembelajaran ini dapat membantu siswa menghafal konsep pelajaran, meningkatkan keterampilan bertanya dan dapat mengomunikasikan pengetahuannya (Nasution, 2017). 
Presentase nilai siswa yang tuntas mengalami peningkatan sebesar $8 \%$, presentase ini menunjukkan bahwa secara klasikal pembelajaran dikatakan tuntas karena nilai presentase telah melebihi $\mathrm{kkm}$ yakni $75 \%$. Sejalan dengan penelitian dari Wahyuningsih (2012) bahwa siswa dikatakan tuntas belajar setelah memperoleh ketuntasan $\geq 75 \%$ (30 dari 40) siswa tuntas secara klasikal. Dari tes hasil belajar pada kelas XI IPA 1 diperoleh nilai $\geq 71$ sejumlah 36 dari 40 siswa, sehingga perangkat pembelajaran yang dikembangkan efektif untuk meningkatkan hasil belajar siswa. Jadi, dapat dikatakan bahwa metode PQ4R dapat meningkatkan hasil belajar IPA kelas V Al-Kholiq SDN Muhammadiyah 8 Surabaya.

\section{KESIMPULAN DAN SARAN}

Penerapan metode pembelajaran PQ4R dalam pembelajaran IPA berhasil dengan tingkat keberhasilan sangat baik. Hal ini dapat dilihat dari peningkatan tiap siklusnya. Prosentase ketuntasan belajar siswa di siklus I yaitu $72 \%$. Sedangkan prosentase pelaksanaan pembelajaran di siklus II yaitu $80 \%$. Dengan demikian, dapat diketahui bahwa terjadi peningkatan pada pelaksanaan pembelajaran IPA dengan menerapkan metode PQ4R sebanyak $8 \%$. Sehingga dapat disimpulkan bahwa metode PQ4R dapat meningkatkan hasil belajar IPA di SD. Berdasarkan hasil penelitian maka disarankan bahwa untuk menghasilkan pembelajaran yang berkualitas dan hasil belajar tinggi maka diperlukan perangkat pembelajaran yang baik.

\section{DAFTAR RUJUKAN}

Daryanto. (2014). Penelitian Tindakan Kelas dan Penelitian Tindakan Sekolah beserta contoh-contohnya. Yogyakarta: Gava Media.

Indrawati, T., Riyadi, \& Matsuri. (2014). PENGARUH METODE PEMBELAJARAN PREVIEW, QUESTION, READ, REFLECT, RECITE, AND REVIEW (PQ4R) TERHADAP KEMAMPUAN MEMBACA PEMAHAMAN. Jurnal Didaktika Dwija Indria, 2(9), 1-6.

Nasution, N. H. (2017). Pengaruh model pembelajaran pq4r terhadap hasil belajar siswa kelas X SMA materi ekosistem. Proceeding Of Biology Education, $1(1), 24-29$.

Rahayu, H., \& Hartati, S. (2016). Peningkatan Kualitas Pembelajaran Ipa Melalui Strategi Belajar Pq4R Berbantuan Media Powerpoint. Jurnal Phenomenon (Pendidikan MIPA), 6(1), 35-44.

Suprijono, A. (2015). Cooperative Learning (PAIKEM Theory And Application). Yogyakarta: Pustaka Belajar.

Tandililing, E. (2011). Peningkatan Komunikasi Matematis Serta Kemandirian BelajarSiswa SMA Melalui Strategi PQ4R Disertai Bacaan Refutation Text. Untan (Pendidikan IPA Dan Matematika), 2(1), 11-22.

Trianto Ibnu Badar Al-Tabany, \& Tutik, T. T. (2014). Mendesain model Pembelajaran Inovatif, Progresif, dan Konstektual: Konsep, Landasan, dan Implementasinya pada Kurikulum 2013. Jakarta: Prenadamedia Group.

Wahyuningsih, A. N. (2012). PENGEMBANGAN MEDIA KOMIK BERGAMBAR MATERI SISTEM SARAF UNTUK PEMBELAJARAN 
YANG MENGGUNAKAN STRATEGI PQ4R. Journal of Innovative Science Education, 1(1), 1-9.

Widayati, A. (2008). Penelitian Tindakan Kelas. Jurnal Pendidikan Akuntasi Indonesia, VI(1), 87-93.

Wondal, R. (2016). Penggunaan Model Pembelajaran Preview, Questions, Read, Reflect, Recite, Review (Pq4r) Untuk Meningkatkanaktivitas Dan Hasil Belajar Biologi. Jurnal Pendidikan Dasar, 7(1), 128-139.

Yulistiati, A., Rosyidi, A., \& Ariyanto, J. (2012). Hasil belajar biologi ditinjau dari metode pembelajaran preview, question, read, reflect, recite, review (PQ4R) dan minat belajar siswa kelas $\mathrm{x}$ SMA negeri 1 kebakkramat tahun pelajaran 2011/2012. BIO-PEDAGOGI Volume 1, Nomor 1, 1(1), 1-12. 